\title{
Potential effects of human pressure and habitat fragmentation on population viability of the Antillean manatee Trichechus manatus manatus: a predictive model
}

\author{
Delma Nataly Castelblanco-Martínez ${ }^{1, *}$, Coralie Nourisson $^{2}$, Ester Quintana-Rizzo ${ }^{3}$, \\ Janneth Padilla-Saldivar ${ }^{1}$, Juan J. Schmitter-Soto ${ }^{1}$ \\ ${ }^{1}$ El Colegio de la Frontera Sur, Av. Centenario km 5.5, Chetumal, Quintana Roo, Mexico \\ ${ }^{2}$ GEOMARE, Av. Miguel Alemán 616-4B, Col. Lázaro Cárdenas, Mazatlán, 82040 Sinaloa, Mexico \\ ${ }^{3}$ University of South Florida, 140 7th Avenue South, St. Petersburg, Florida 33701, USA
}

\begin{abstract}
We present a population viability analysis for the metapopulation of the Antillean manatee Trichechus manatus manatus with the aim of predicting its tendencies under various hypothetical scenarios of conservation. Multiple individual Monte Carlo simulations of deterministic and stochastic factors were run on VORTEX 9.73 software. Populations were defined using genetic structure, geographic barriers, and typical ranging behavior. Demographic characteristics and life history parameters were inferred from the most recent compilation of information on the subspecies or were extrapolated from the Florida manatee T. m. latirostris. The baseline model describes a metapopulation with a positive growth. This model was sensitive to changes in mortality, but did not show any significant response to variations in assumed carrying capacity, age at first reproduction, maximum reproductive age, or initial population size. We simulated different scenarios by modifying human pressure, habitat fragmentation, and catastrophic events (i.e. hurricanes). Additional combined models were developed to simulate the best- and worst-case scenarios for human pressure level and fragmentation. The model suggested that the metapopulation would not be able to withstand an annual anthropogenically induced mortality rate $>5 \%$. A decrease in the survival of transient individuals could also lead to a decline of the population. Variations of the hurricane parameters did not yield important changes in the population curves, but other effects of climatic change are discussed. The extensive geographical area used by manatees requires international collaboration to ensure the protection of the metapopulation through effective conservation strategies across countries.
\end{abstract}

KEY WORDS: Population ecology - Trichechus manatus manatus · Human-related mortality · Connectivity $\cdot$ Tropical ecosystems $\cdot$ VORTEX

\section{INTRODUCTION}

Knowledge of the viability of populations is crucial in order to elucidate the requirements for species persistence (Shaffer 1990). Population viability analysis (PVA) is the use of quantitative methods to predict the likely future status of a population of conserva- tion concern (Morris et al. 2002). PVA has 2 defining characteristics: an explicit model of the extinction process and the quantification of threats to survival. Generally, the extinction model considers 2 categories of factors: deterministic and stochastic. Singly or combined, these forces have reduced many wildlife populations to low numbers, and some, to extinc- 
tion (Miller \& Lacy 2005). The analysis involves the prediction of the extinction (or quasi-extinction) probability using analytic (Ludwig 1996) or computer simulation techniques (Lindenmayer et al. 1995).

Manatees (Sirenia: Trichechidae) are classified as 3 species of the genus Trichechus: T. manatus, T. inunguis, and T. senegalensis. The Antillean manatee subspecies T. manatus manatus occurs from northern Mexico to the northeastern coast of Brazil in a patchy distribution. It is the most adaptable member of the family, occupying marine, estuarine, and freshwater areas (Lefebvre et al. 2001). The status of the Antillean manatee varies among countries from vulnerable to endangered to locally extinct. Estimates by country range from 10 to 1000 animals, with the largest populations reported from Mexico to Belize (Quintana-Rizzo \& Reynolds 2010). Manatee populations and their available habitat have declined (Deutsch et al. 2008). In recent decades, the populations of the Antillean manatee have been affected by natural catastrophes (hurricanes) and anthropogenic actions such as hunting, habitat loss, entanglement in fishing gear, boat collisions, and pollution (QuintanaRizzo \& Reynolds 2010). For Florida manatees, the recovery from their depleted state has been slow (Langtimm et al. 1998) due to the low fecundity and reproductive rate of the species (Rathbun et al. 1995). It is expected that Antillean manatees face the same situation. The cumulative actions of natural catastrophes, anthropogenic disturbances, and low recovery rates can cause a progressive decrease in the population throughout the distribution range. For all of these reasons, T. m. manatus is considered Endangered on the IUCN Red List of Threatened Species (Self-Sullivan \& Mignucci-Giannoni 2008).

The first PVA for a sirenian population was developed for the Florida manatee Trichechus manatus latirostris (Marmontel et al. 1997). Other PVAs include the Antillean manatee populations of Costa Rica (Jiménez-Pérez 1998) and Mexico (Guichard et al. 2001). Additionally, PVAs have also been used to investigate the viability of 2 metapopulations of dugong, another member of the order Sirenia, under varying regimes of indigenous hunting (Heinsohn et al. 2004). However, no attempt has yet been made to model the viability of the entire Antillean manatee metapopulation. A metapopulation consists of a system of spatially separated populations of the same species which interact at some level, connected by dispersing individuals (Hanski \& Gilpin 1991). The distribution of the Antillean manatee is discontinuous, mostly due to coastal border fragmentation and marine currents, making it suitable for treatment as a metapopulation.
Our objective was to develop a PVA for the entire Antillean manatee metapopulation, in order to identify the way in which fragmentation, environmental uncertainty, demographic stochasticity, and reproductive factors are interrelated and contribute to the extinction process. We developed projections of the extinction trends of the metapopulation under various hypothetical scenarios to understand how the subspecies could be affected. The results of the model were used to provide recommendations to policy and decision makers that could help develop appropriate management plans for the subspecies.

\section{METHODS \\ Overview}

The Antillean manatee model was built using the software VORTEX 9.73 (Miller \& Lacy 2005), which is an individual-based simulation model for PVA. VORTEX is a popular tool to model the extinction probability of small populations and analyzes the effects of deterministic forces as well as demographic, environmental, and genetic stochastic events on the dynamics of wildlife populations (Lacy 2000b). A minimum viable population is one of sufficient size to endure the effects of perturbations within its particular biogeographic context (Shaffer 1981). Input information required by VORTEX includes metapopulation structure, demographic characteristics, migratory dynamics, life history parameters, environmental effects, and anthropogenic causes of mortality. On the basis of these parameters, the software predicts the extinction risk within a specific time interval, the probability of persistence, and the mean size of the final population (Lindenmayer et al. 1993, Miller \& Lacy 2005). A baseline model was created with biological parameters taken from previous research on other manatee species or subspecies, mainly the Florida manatee Trichechus manatus latirostris. However, some important variations were made for the Antillean manatee model, as explained in the following section.

\section{Baseline model parameters}

Metapopulation structure

We divided the metapopulation into subpopulations based on genetic, geographic, and ecological 
criteria. The mtDNA phylogeny for Trichechus manatus indicates that there are 3 lineages: (1) Florida and the West Indies, (2) the Gulf of Mexico and Antillean rivers of South America, and (3) the northeastern coast of South America (Garcia-Rodriguez et al. 1998). The Florida population was not included in this study because it has been classified as a separate subspecies, T. m. latirostris, based on morphological characteristics (Domning \& Hayek 1986). Using this genetic division, the isolation level between subpopulations was estimated from obvious geographic characteristics, local genetic structure, ranging behavior, and habitat use, to determine the most likely subpopulations. Specific arguments to determine the separation between subpopulations are described in the following.

Data from the Bahamas were not included in the analysis because all local sightings correspond to Trichechus manatus latirostris (Lefebvre et al. 2001). Two likely genetic barriers exist (Vianna et al. 2006); the first isolates the Greater Antilles from the continental populations, and the other separates the coast of South America from Guyana to Brazil (Fig. 1). We took into account the ranging movements of the species, which mainly occur along coastlines, as manatees rarely venture across open oceans. This latter behavior appears to be related to water depth, lack of vegetation for food, increased predation in offshore waters, and lack of fresh water (Reynolds \& Ferguson 1984). Therefore, we assumed that the transit of individuals between the Greater Antilles and the continent, and vice versa, is unlikely.

Two distinct genetic populations appear to exist in Mexico: one along the Caribbean coast and one in the riverine systems connected to the Gulf of Mexico (Nourisson et al. 2011). For this reason, the manatee population inhabiting the Gulf of Mexico was separated from the Caribbean population.

The Colombian population was separated from Mesoamerica because strong currents and submarine canyons could prevent the transit between these 2 subpopulations. Manatees have been reported in the southern part of the Gulf of Uraba (northern Colombia), but no sightings have been recorded near the Panama border (Caicedo-Herrera et al. 2005).

Thus, the metapopulation was divided into 6 subpopulations (Fig. 1): Subpopulation 1: Greater Antilles (Puerto Rico, Jamaica, Dominican Republic, Haiti, and Cuba); Subpopulation 2: Gulf of Mexico (Gulf coast of Mexico); Subpopulation 3: Mesoamerica (Caribbean coast of Mexico, Belize, Guatemala, Honduras, Nicaragua, Costa Rica, and Panama); Subpopulation 4: Coasts of Colombia; Subpopulation 5: Orinoquia, Venezuelan coasts, and Lesser Antilles; and Subpopulation 6: Guyana, Suriname, French Guiana, and coastal Brazil.

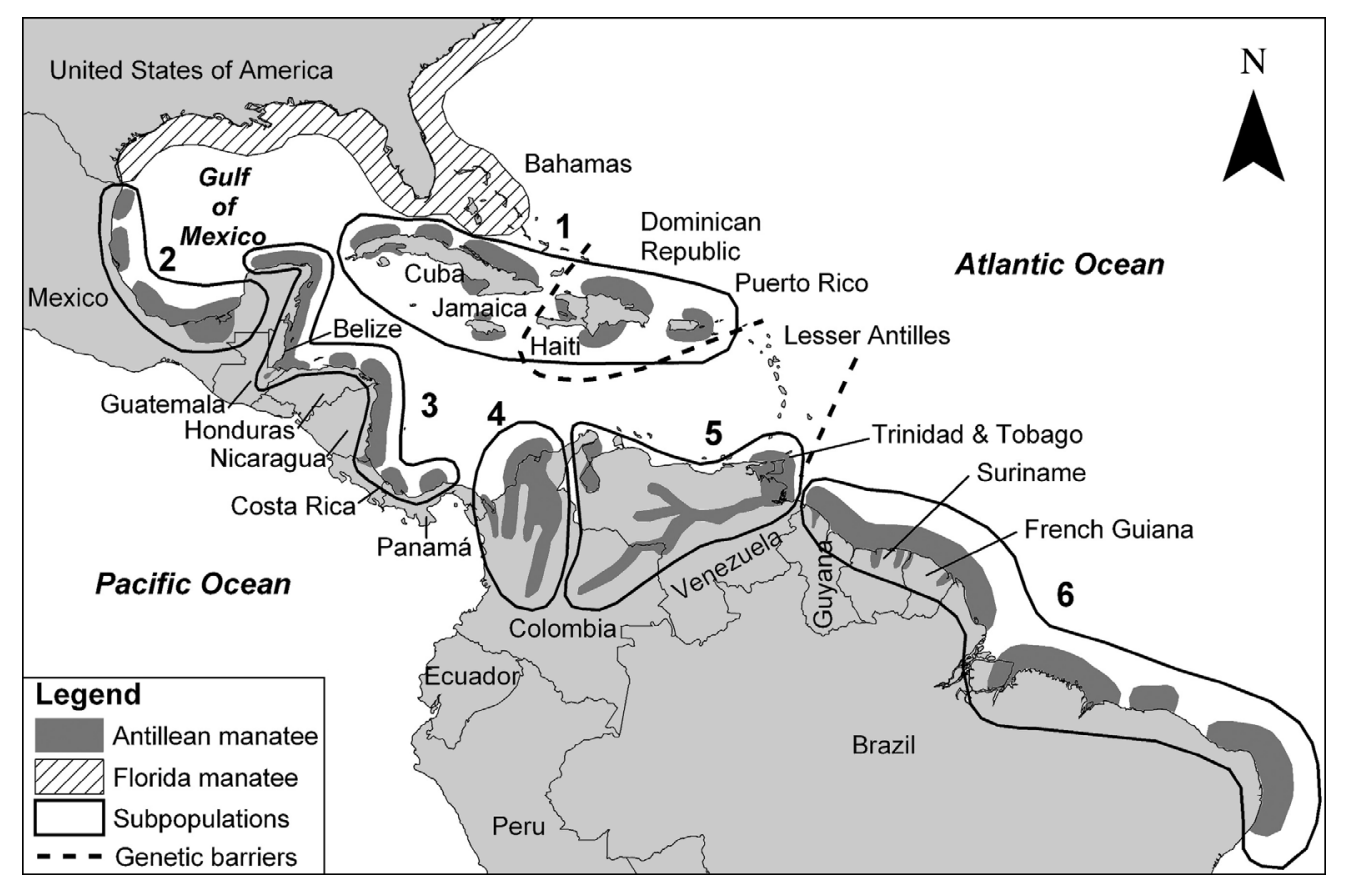

Fig. 1. Antillean manatee Trichechus manatus manatus subpopulations (Polygons 1-6) used for the analysis. Dark grey area shows the distribution of Antillean manatees; hatched area shows that of Florida manatees T. m. latirostris. Dashed lines are likely genetic barriers (Vianna et al. 2006) 


\section{Demographic characteristics and} migratory dynamics

The information on population size was based on the most recent compilation of information available for the species in the Regional Management Plan for the West Indian Manatee of the United Nations Environment Programme (Quintana-Rizzo \& Reynolds 2010). Some data were updated by personal communications with local experts (Table 1).

Recent studies have not detected high levels of inbreeding in various manatee populations (Hunter et al. 2010, Nourisson et al. 2011), because the occasional long-distance movements between subpopu- lations could maintain the heterozygosity observed within those studied populations. Furthermore, movements between subpopulations are more likely to occur along the coasts due to the behavioral characteristics and habitat requirements. Therefore, we did not assume inbreeding depression.

We assumed low migration rates, based on the fact that currents and other geographic factors can affect the movement of individuals between subpopulations (Jiménez-Pérez 1998). We arbitrarily set a migration rate of $2 \%$ between neighboring subpopulations, e.g. between the Gulf of Mexico and Mesoamerica (subpopulations 2 and 3, Fig. 1), and 1\% between non-neighboring subpopulations, e.g. be-

Table 1. Trichechus manatus manatus. Population size estimates and subpopulations of Antillean manatees used as input for the model. Adapted from Quintana-Rizzo \& Reynolds (2010). S: stable, D: declining, U: unknown

\begin{tabular}{|c|c|c|c|c|}
\hline Subpopulation & $\begin{array}{l}\text { Possible } \\
\text { trend }\end{array}$ & $\begin{array}{c}\text { Minimum } \\
\text { population size }\end{array}$ & $\begin{array}{c}\text { Estimated } \\
\text { population size }\end{array}$ & Source \\
\hline \multicolumn{5}{|l|}{ 1. Greater Antilles } \\
\hline Puerto Rico (US) & $\mathrm{S}$ & 300 & 450 & J. Collazos (pers. comm.) \\
\hline Jamaica & U/D & 50 & 50 & Quintana-Rizzo \& Reynolds (2010) \\
\hline Dominican Republic & $\mathrm{D}$ & $30-45$ & 200 & H. Domínguez (pers. comm.) \\
\hline Haiti & $\mathrm{U}$ & 8 & 100 & Quintana-Rizzo \& Reynolds (2010) \\
\hline Cuba & $\mathrm{U} / \mathrm{D}$ & $\mathrm{U}$ & 500 & A. Álvarez-Alemán (pers. comm.) \\
\hline Total & & & 1300 & \\
\hline \multicolumn{5}{|l|}{ 2. Gulf of Mexico } \\
\hline Gulf of Mexico & $\mathrm{U}$ & $1000-2000$ & 1250 & Quintana-Rizzo \& Reynolds (2010) \\
\hline Total & & & 1250 & Quintana-Rizzo \& Reynolds (2010) \\
\hline \multicolumn{5}{|l|}{ 3. Mesoamerica } \\
\hline Caribbean Mexico & $\mathrm{U}$ & 220 & 250 & Quintana-Rizzo \& Reynolds (2010) \\
\hline Belize & $\mathrm{U} / \mathrm{D}$ & $400-700$ & 1000 & N. Auil (pers. comm.) \\
\hline Guatemala & $\mathrm{U}$ & $53 \pm 44(\mathrm{SD})$ & 150 & E. Quintana-Rizzo (pers. obs.) \\
\hline Honduras & $\mathrm{S}$ & 11 & 100 & Quintana-Rizzo \& Reynolds (2010) \\
\hline Nicaragua & $\mathrm{D}$ & 71 & 500 & Quintana-Rizzo \& Reynolds (2010) \\
\hline Costa Rica & $\mathrm{D}$ & $31-66$ & 200 & C. Espinoza-Marín (pers. comm.) \\
\hline Panama & $\mathrm{U}$ & $10-100$ & 150 & K. Ruiz (pers. comm.) \\
\hline Total & & & 2350 & \\
\hline \multicolumn{5}{|l|}{ 4. Colombia } \\
\hline $\begin{array}{l}\text { Colombia (Pacific and } \\
\text { Caribbean region) }\end{array}$ & $\mathrm{U} / \mathrm{D}$ & $100-1000$ & 400 & Quintana-Rizzo \& Reynolds (2010) \\
\hline Total & & & 400 & \\
\hline \multicolumn{5}{|l|}{ 5. Venezuela } \\
\hline Trinidad and Tobago & $\mathrm{D}$ & $25-30$ & 100 & Quintana-Rizzo \& Reynolds (2010) \\
\hline Colombia (Orinoco Region) & $\mathrm{D}$ & $\mathrm{U}$ & 100 & D. N. Castelblanco-Martínez (pers. obs.) \\
\hline $\begin{array}{l}\text { Venezuela (Caribbean and } \\
\text { Orinoco regions) }\end{array}$ & $\mathrm{D}$ & $\mathrm{U}$ & 200 & A. Manzanilla (pers. comm.) \\
\hline Total & & & 400 & \\
\hline \multicolumn{5}{|l|}{ 6. Brazil } \\
\hline French Guiana & $\mathrm{S}$ & $\mathrm{U}$ & 100 & Quintana-Rizzo \& Reynolds (2010) \\
\hline Guyana & $\mathrm{D}$ & $\mathrm{U}$ & 100 & Quintana-Rizzo \& Reynolds (2010) \\
\hline Suriname & $\mathrm{D}$ & $\mathrm{U}$ & 100 & Quintana-Rizzo \& Reynolds (2010) \\
\hline Brazil & $\mathrm{U} / \mathrm{D}$ & $155-1447$ & 700 & J. Borges (pers. comm.) \\
\hline Total & & & 1000 & \\
\hline Total for all populations & & & 6700 & \\
\hline
\end{tabular}


tween Subpopulations 1 and 6 (Fig. 1). It is accepted that manatees acquire their migratory patterns and seasonal ranges from their mothers during the 1.5 to 2 yr dependency period (Deutsch et al. 2003). The dispersal was assumed without distinction of sex or age class, because calves can travel along with their mother. Manatees have a remarkably efficient and responsive immune system (Bossart et al. 2003) and appear to be highly resistant to natural disease processes and lethal effects of traumatic injury (Buergelt et al. 1984). Thus, a $95 \%$ survival probability was arbitrarily assigned to transients during migration.

Finally, all growing populations are constrained by one or more limiting resources that slow or prevent continued growth when populations become large. This density-dependent growth leads to the general observation that large populations tend to grow more slowly, or even shrink, relative to small populations, as is the case with the Florida manatee population (Haubold et al. 2006). A primary limiting factor for the population growth of Florida manatees is believed to be the availability of warm water refugia during periods of prolonged cold weather in winter (Haubold et al. 2006). However, this is not a factor that could limit the growth of the Antillean manatee population through intraspecific competition. High-density effects on reproduction have not yet been observed or inferred for the Antillean manatee. The conventional density-dependence model for population growth is based on the premises that populations have the potential to increase exponentially and that there is a density-dependent feedback that progressively reduces the actual rate of increase (Hassell 1975). In the case of Antillean manatees, this is probably not an issue, given the low densities of the subspecies. Additionally, an Allee effect, or inverse density dependence at low density (Courchamp et al. 1999), would probably not affect manatees. Manatees are semisocial mammals (Reynolds 1979) that do not need a group effect to successfully mate, do not need others for their survival, and travel long distances to find a mate. Thus, similar to other PVAs of sirenian populations (Marmontel et al. 1997, Jiménez-Pérez 1998, Heinsohn et al. 2004), this model did not assume density dependence in reproduction.

\section{Life history parameters}

Parameters included in the model were: reproductive system, age at first reproduction (hereafter, age at first offspring, FO), maximum age at reproduction, maximum age, maximum number of broods per year, maximum number of progeny per brood, percentage of 1 progeny and twins per brood, sex ratio, percentage of adult females breeding, percentage of males in the breeding pool, and natural mortality rates (Table 2).

Table 2. Trichechus manatus manatus. Life history and environmental parameters used for the baseline model. Data were extrapolated from the sources indicated. EV: variation due to the environment. See 'Methods' for details. na: not applicable

\begin{tabular}{|c|c|c|c|}
\hline Parameter & Reported range & Value used & Source \\
\hline Reproductive system & Polygynous & Polygynous & Marmontel et al. (1997) \\
\hline Age at first reproduction (yr) & $3-6$ & 6 & O'Shea \& Hartley (1995) \\
\hline Maximum age at reproduction (yr) & $27-39$ & 39 & Marmontel et al. (1997) \\
\hline Maximum age (yr) & na & 60 & Marmontel et al. (1996) \\
\hline Maximum no. of broods $\mathrm{yr}^{-1}$ & na & 1 & Marmontel et al. (1997) \\
\hline Maximum no. of progeny brood ${ }^{-1}$ & $1-2$ & 2 & Marmontel et al. (1997) \\
\hline One progeny per brood (\%) & na & 98.6 & Rathbun et al. (1995) \\
\hline Twins per brood (\%) & na & 1.4 & Rathbun et al. (1995) \\
\hline Sex ratio at birth in \% of males & na & 50 & Marmontel et al. (1997) \\
\hline$\%$ female adults breeding & na & 33 & Marmontel et al. (1997) \\
\hline$\%$ males in breeding pool & na & 45 & Marmontel et al. (1997) \\
\hline Natural mortality rates (\%) & & & Jiménez-Pérez (1998) \\
\hline Age $0-1$ & na & $18(\mathrm{EV}=1.8)$ & Jiménez-Pérez (1998) \\
\hline Age 1 & na & $5(\mathrm{EV}=0.5)$ & Jiménez-Pérez (1998) \\
\hline EV correlation between subpopulations (\%) & na & 75 & Jiménez-Pérez (1998) \\
\hline Negative environmental effect on survival (\%) & na & 10 & Marmontel et al. (1997) \\
\hline Negative environmental effect on reproduction (\%) & na & 5 & Marmontel et al. (1997) \\
\hline Carrying capacity ( $K$; no. of individuals) & na & 13400 & Present study \\
\hline \multicolumn{4}{|l|}{ Frequency of hurricanes } \\
\hline Subpops. 1, 2, $3(\%)$ & na & 0.5 & Marmontel et al. (1997) \\
\hline Subpops. 4, 5, $6(\%)$ & na & 0.1 & Present study \\
\hline
\end{tabular}


Although there has been no study specifically devoted to mating behavior, scramble promiscuity implying polygyny and androgyny-has been securely established as the manatee mating pattern (Rathbun et al. 1995, Anderson 2002). Long-term photo-identification studies show that adult manatees have an annual survival rate of about $96 \%$ in the Florida population, with relatively low humanrelated mortality (Langtimm et al. 2004). Analysis of growth layers in the earbone indicates that manatees can live up to $60 \mathrm{yr}$ in the wild (Marmontel et al. 1996), so we took 60 as the oldest age. Captive manatees are known to live up to $63 \mathrm{yr}$ or more (R. K. Bonde pers. comm.)

Age at FO was determined as follows. The median age at first reproduction for females is about $5 \mathrm{yr}$, with some individuals giving birth at Age 4 and most by Age 7 (Marmontel 1995, O'Shea \& Hartley 1995, Rathbun et al. 1995). Although males undergo spermatogenesis as young as 2 to $3 \mathrm{yr}$ of age (Hernández et al. 1995), the age at which they sire and produce their first offspring is unknown. Therefore, we assumed the age at FO to be $6 \mathrm{yr}$ for both females and males.

Gestation lasts between 11 and 13 mo (Rathbun et al. 1995, Reid et al. 1995, Pomeroy 2011). The typical litter size is one, with twins reported rarely (Marmontel 1995, Odell et al. 1995, O'Shea \& Hartley 1995, Rathbun et al. 1995). Values for single (98.6\%) and twin $(1.4 \%)$ births were adopted from Rathbun et al. 1995. Calves have been observed feeding on plants just after birth (Hartman 1979), but dependence on milk can last up to 18 mo or more (O'Shea \& Hartley 1995, Rathbun et al. 1995, Reid et al. 1995). Interbirth intervals average 2.5 to $3 \mathrm{yr}$, when the calf survives to weaning (Marmontel 1995, Rathbun et al. 1995, Reid et al. 1995). Thus, we used $33 \%$ of adult females breeding each year. There is no conclusive evidence on reproductive senescence in manatees, but free-ranging females are known to continue reproducing at least into their thirties (Marmontel 1995). Therefore, we used $39 \mathrm{yr}$ as the maximum age at reproduction.

It is recognized that rates and causes of mortality are likely to differ between Florida and Antillean manatees. Florida manatees are at the northern part of the range of distribution and they are naturally affected by diseases (Buergelt et al. 1984), starvation, and complication during parturition (Ackerman et al. 1995). Cold stress and red tides could cause massive death of individuals, especially young and calves (Walsh et al. 2007). In contrast, in the tropics, water temperature remains in the optimal range for mana- tees, which is probably $>20^{\circ} \mathrm{C}$ (Irvine 1983), and provides no risk to the manatee population. However, physiological changes have been observed in manatees that inhabit very warm water temperatures $\left(>35^{\circ} \mathrm{C}\right.$, see Bossart et al. 2003). The massive death of manatees reported in Florida due to exposure to neurotoxins produced by the dinoflagellate Karenia brevis has not been reported in the tropics. Instead, disease, perinatal death (Mignucci-Giannoni et al. 2000), and, in a small proportion, predation (FalconMatos et al. 2003) could be the most common natural causes of mortality of the Antillean manatees. Thus, our model used similar values of natural mortalities reported for the manatee Trichechus manatus manatus population in Costa Rica (Jiménez-Pérez 1998); data are summarized in Table 2.

\section{Environmental effects}

Sources of environmental variation (e.g. weather, predator and prey population densities, parasite loads) can affect reproduction and survival independently or simultaneously (Miller \& Lacy 2005). We assumed a random environmental effect on reproduction and survival rates, and an environmental correlation of $75 \%$ between subpopulations (Jiménez-Pérez 1998). Although discontinuous, the entire metapopulation is located in the tropical range, and large environmental phenomena could affect it as a whole. There are no estimates of carrying capacity ( $K_{;}$no. of individuals) for Antillean manatees, either because the population is too small for resources to become limiting, or because of the absence of monitoring programs powerful enough to detect such change. However, the current extended availability of suitable habitats for manatees along the distribution area, such as seagrass beds (Short et al. 2007) and mangrove ecosystems (Giri et al. 2011), indicates that Antillean manatee populations are currently below their carrying capacities. Therefore, $K$ was set at double the current estimated metapopulation size. Nevertheless, habitat loss is considered one of the main threats to the species, and in the future it could become a relevant issue. No environmental variation was added to $K$. The variation on mortality rates due to natural environmental variation was set to $10 \%$ of the mean of the mortality rates (JiménezPérez 1998).

Empirical evidence suggests that manatee survival may be affected by severe storm events. Hurricanes and tropical storms can cause manatee mortality by wounding, beaching (due to storm surge or injury 
from debris in turbulent water), or displacing manatees by storm currents into areas unsuitable for their survival (Langtimm \& Beck 2003, Langtimm et al. 2006). Those environmental phenomena might also affect survival through the destruction or removal of vegetation, as has been the case with dugongs (Heinsohn \& Spain 1974, Preen \& Marsh 1995). Hurricanes were included in the model as global catastrophes (i.e. hurricanes have the potential to affect all manatee subpopulations). However, the probability that these will affect manatees varies from one subpopulation to another. Hurricanes have a greater effect in the Gulf of Mexico, Caribbean, and Mesoamerica than on the coast of South America. For example, in Colombia, the possibility of hurricanes affecting the mainland is quite small because the Sierra Nevada de Santa Marta, north of Colombia, acts as a barrier that reduces the force of the winds (Ortiz-Royero 2007). Furthermore, the South American coast is rarely affected by hurricanes, since most are formed in the north Atlantic, off the coast of Africa. Therefore, the frequency of hurricane occurrence was set to $0.5 \%$ for subpopulations 1,2 , and 3 (to be consistent with Marmontel et al. 1997) and to $0.1 \%$ for the other subpopulations. The negative effect of hurricanes on reproduction and survival was set to 5 and $10 \%$, respectively (Marmontel et al. 1997).

\section{Anthropogenic causes of mortality}

Poaching of Antillean manatees for human consumption has prehistoric origins (McKillop 1985), and has been reported in almost all of the areas where the subspecies is distributed (Quintana-Rizzo \& Reynolds 2010). In some floodplain areas, incidental drowning of the Antillean manatee in fishing nets is the main cause of mortality (CastelblancoMartínez et al. 2009). Other causes of mortality, such as collisions with motor boats, have been reported, but they are uncommon (Mignucci-Giannoni et al. 2000, Borges et al. 2007).

We use the term 'human-related mortality' to refer to hunting, entanglement, and collisions with boats. There is inconsistent information about general human-related mortality of the metapopulation, although some local reports exist. For example, in Chetumal Bay, Mexico, $0.31 \%$ of manatee deaths per year between 1990 and 2007 were attributed to anthropogenic causes (Morales-Vela et al. 2002, Morales-Vela \& Padilla-Saldívar 2009). This means that 1 manatee died every 2 yr due to human factors. For the Orinoco Basin (Colombia, Venezuela), studies report a human-related death range from 1 to 10 manatees $\mathrm{yr}^{-1}$ from 1980 to 2004 (CastelblancoMartínez et al. 2009), on average 3.8 ind. $\mathrm{yr}^{-1}$ (around $1.2 \%$ of the assumed Orinoco population). Assuming that all subpopulations experience approximately the same human pressure, we arbitrarily set the baseline model to $1 \%$ of each subpopulation dying from anthropogenic causes every year. We assumed that females and males have the same probability of being caught. Poachers prefer to hunt adults over calves because adults have more meat for consumption. However, young and juveniles are more frequently caught in fishing nets, as large animals can usually break through the nets (Castelblanco-Martínez et al. 2003). Since adults are more vulnerable to hunting, and young animals to entanglement, in the input model we assumed the same probability of human-related mortality for all age classes. The occurrence of orphan calves as a collateral consequence of separation from the mother was not included as a mortality source, because no estimates were available about the percentage of calves that die due to this factor.

\section{Simulation parameters}

\section{Sensitivity test of the baseline model}

Models can be more sensitive to some parameters than others; therefore, sensitivity tests were conducted to identify areas of uncertainty in several of the parameter values (mortality rates, $K_{i}$ no. of individuals, age at FO, initial population size, and maximum age), allowing us to estimate how large an error in these parameters could affect the simulation results. We ran 500 simulations for each separate parameter to test model sensitivity, and ran the model for $200 \mathrm{yr}$ (Table 3).

\section{Modeling}

Different scenarios were simulated by modifying specific parameters simultaneously for humanrelated mortality, habitat fragmentation, and catastrophic events (Table 4). Additionally, a series of models combining several levels of those parameters was developed. The worst- and best-case scenarios were simulated and compared with the baseline model. VORTEX ran 500 iterations in a simulated period of 500 yr. The quasi-extinction level was defined as $\mathrm{N}<670$ ind., i.e. $10 \%$ of the inferred current population (Heinsohn et al. 2004). 
Table 3. Trichechus manatus manatus. Variation/modification in selected parameters used to evaluate the sensitivity of the model. Baseline values are in bold. Baseline parameters were taken from data collected on the Florida manatee (Table 2), except the initial metapopulation size (Table 1) and the carrying capacity ( $K$; no. of individuals; Table 2 )

\begin{tabular}{|c|c|}
\hline Parameter & Values \\
\hline Mortality rates & $\begin{array}{l}\text { Half of baseline parameters, } \\
\text { baseline parameters, double } \\
\text { baseline parameters }\end{array}$ \\
\hline Carrying capacity & 13400,6700 \\
\hline $\begin{array}{l}\text { Age at first reproduction } \\
\text { (yr) }\end{array}$ & $3,5,6$ \\
\hline Max. reproductive age (yr) & $27,35,39$ \\
\hline $\begin{array}{l}\text { Initial metapopulation } \\
\text { size (no. ind.) }\end{array}$ & $1675,3350,6700,13400$ \\
\hline Max. age (yr) & $50, \mathbf{6 0}, 65$ \\
\hline
\end{tabular}

Table 4. Trichechus manatus manatus. Variation in the factors used to evaluate the viability of the metapopulation. Human-related mortality (\%) is based on the number of individuals dying in each population per year; habitat fragmentation shows the \% survival of transients; and catastrophic events the \% frequency of hurricanes. Baseline values are in bold

\begin{tabular}{|c|c|c|}
\hline Factor & Definition & \\
\hline \multicolumn{3}{|c|}{ 1. Human-related mortality (\% ind. pop. ${ }^{-1} \mathrm{yr}^{-1}$ ) } \\
\hline Level 0 & \multicolumn{2}{|c|}{ No human-related mortality } \\
\hline Level 1 & \multicolumn{2}{|l|}{1} \\
\hline Level 2 & \multicolumn{2}{|l|}{2} \\
\hline Level 3 & \multicolumn{2}{|l|}{3} \\
\hline Level 4 & \multicolumn{2}{|l|}{4} \\
\hline Level 5 & \multicolumn{2}{|l|}{5} \\
\hline Level 6 & \multicolumn{2}{|l|}{10} \\
\hline Level 7 & \multicolumn{2}{|l|}{30} \\
\hline \multicolumn{3}{|c|}{ 2. Habitat fragmentation ( $\%$ survival) } \\
\hline Level 1 & \multicolumn{2}{|l|}{95} \\
\hline Level 2 & \multicolumn{2}{|l|}{70} \\
\hline Level 3 & \multicolumn{2}{|l|}{50} \\
\hline Level 4 & \multicolumn{2}{|l|}{30} \\
\hline Level 5 & \multicolumn{2}{|l|}{10} \\
\hline \multicolumn{3}{|c|}{ 3. Catastrophic events ( $\%$ frequency) } \\
\hline & Subpops. 1, 2, 3 & Subpops. $4,5,6$ \\
\hline Level 0 & 0 & 0 \\
\hline Level 1 & 0.5 & 0.1 \\
\hline Level 2 & 1 & 0.6 \\
\hline Level 3 & 2 & 1.2 \\
\hline
\end{tabular}

Human-related mortality

In order to model variations in the intensity of human-related mortality, we simulated several levels of this parameter: $0 \%$ (the ideal situation), $1 \%$ (baseline), and $2,3,4,5,10$, and $30 \%$ to simulate different rates of human pressure and their impact on survival.
These rates were applied to all subpopulations equally, since we did not have information on precise differences between subpopulations.

\section{Habitat fragmentation}

Habitat fragmentation is defined as the process of creation of habitat 'islands' of different sizes, with important consequences for the physical environment as well as for the biota (Saunders et al. 1991). The major effect of habitat fragmentation on a metapopulation is the disruption of biological corridors and, therefore, a decrease in connectivity (Saunders et al. 1991). Corridors are strips of habitat with a biologically designed or incidental function of increasing dispersal among populations (Akçakaya et al. 2007). Functional connectivity, understood as the degree to which landscapes actually facilitate or impede the movement of organisms and processes (e.g. reproduction: Uezu et al. 2005), can be inferred by the survival of transient manatees moving between adjacent subpopulations. We modeled 5 different levels of survival of transients: $95 \%$ (baseline), and 70,50,30, and 10\%, to simulate the effects of habitat fragmentation.

\section{Catastrophic events}

Global climate change is expected to affect temperature and precipitation patterns, oceanic and atmospheric circulation, rate of sea level rise, and the frequency, intensity, timing, and distribution of hurricanes and tropical storms (Michener et al. 1997). Hurricanes can decrease the viability of manatees due to direct mortality, indirect mortality, and emigration from the region as a consequence of storms. Also, important seagrass communities can be severely damaged by tropical storms, affecting the feeding resource for manatees (Langtimm \& Beck 2003). For the baseline model we assumed a hurricane frequency of $0.5 \%$ (Subpopulations 1-3) and 0.1\% (Subpopulations 4-6). Thus, we arbitrarily modeled frequencies of $0 \%$ for all subpopulations (deterministic model), 1 and $0.6 \%$; and 2 and $1.2 \%$, for Subpopulations 1 to 3 and Subpopulations 4 to 6 , respectively.

\section{RESULTS}

The baseline model describes a metapopulation with an estimated initial size of 6700 ind. and positive 
growth $(\mathrm{r}=0.032 ;$ Table 5$)$. This is the average metapopulation growth expected based on mean fecundity and mortality rates in the absence of inbreeding, with low human pressure and relatively low frequency of stochastic processes (e.g. occurrence of hurricanes and tropical storms). All subpopulations showed the same growth pattern (Fig. 2A), with the number of individuals increasing until $K$ was reached. The probability of extinction for all the subpopulations was 0. Mesoamerica (Subpopulation 3) has the largest population size and was predicted to have the highest number of extant individuals after $500 \mathrm{yr}$.

In the sensitivity tests, when the natural mortality values were reduced by half (Fig. 2B, Mortality 1), the metapopulation maintained a pattern similar to the baseline-value simulation (Mortality 2). However, when the natural mortality was increased to twice the baseline (Mortality 3), the metapopulation showed a strong break, reaching extinction after only 100 yr. Because the natural mortality of Antillean manatees seems to be lower than that of Florida manatees, reaching levels of Mortality 3 (double the baseline parameters) may be unlikely. A decrease to half of $K$ leads to a non-growing population maintaining the initial population size over time.

Sensitivity tests to changes in the age at $\mathrm{FO}$, the maximum reproductive age (MRA), and maximum age (MA) (data not shown) revealed some differences in the time that $K$ is reached. However, they were not sensitive to possible errors in the estimation of those parameters. Several initial population sizes (IPS) were used to identify how an error in this parameter could affect the simulations. The obtained curves varied slightly, but the growth rate remained positive in all cases (Table 6). We believe that the population size cannot be outside the tested range (IPS $=1675$ to 13400 ), and we consider that $\mathrm{N}=6700$ is a reasonable value.

A reduction in human-related mortality to 0 did not result in a substantial growth of the population, compared with the $1 \%$ baseline model (Fig. 3). This is due to the assumed $K$ of the system, which limits the increase in manatee numbers. Similar curves were obtained with 2, 3, and $4 \%$ values. However, the population showed negative growth $(\mathrm{r}=-0.001)$ when the human-related mortality was $5 \%$ (Table 7 ). This means that the population would be unable to withstand any annual human-related mortality $>5 \%$. However, the estimated time to extinction was $>500$ yr. Humanrelated mortality simulations of 10 and $30 \%$ accelerated the extinction process, with times to extinction of 307 and $283 \mathrm{yr}$, respectively.

Concerning habitat fragmentation, the population showed positive growth with values of transient survival of $95 \%$ (baseline value) and $70 \%$ (Table 7 , Fig. 4). For a survival probability of $50 \%$, the rvalue was still positive, but lower. However, 30 and $10 \%$ survival probabilities led to a negative growth of the population, with time to extinction

Table 5. Trichechus manatus manatus. Predictions of the baseline model for the Antillean manatee, including mean annual rate of population change across the simulations under deterministic (det-r) and stochastic (stoc-r $\pm \mathrm{SD}$ ) models; final number of individuals (N-final \pm SD). Probability of extinction was 0 in all cases. Values for the metapopulation are shown in bold

\begin{tabular}{|lccc|}
\hline Subpopulation & det-r & \multicolumn{1}{c}{ stoc-r } & N-final \\
\hline 1. Greater Antilles & 0.428 & $0.026 \pm 0.027$ & $2595.51 \pm 19.11$ \\
2. Gulf of Mexico & 0.428 & $0.046 \pm 0.027$ & $2499.22 \pm 11.46$ \\
3. Mesoamerica & 0.428 & $0.006 \pm 0.027$ & $4537.97 \pm 156.17$ \\
4. Colombia & 0.124 & $0.1 \pm 0.028$ & $999.96 \pm 10.19$ \\
5. Venezuela & 0.124 & $0.082 \pm 0.027$ & $799.72 \pm 8.06$ \\
6. Brazil & 0.124 & $0.021 \pm 0.023$ & $1994.37 \pm 15.14$ \\
Metapopulation & $\mathbf{0 . 2 7 6}$ & $\mathbf{0 . 0 3 2} \pm \mathbf{0 . 0 2 1}$ & $\mathbf{1 3 4 2 6 . 7 4} \pm \mathbf{1 6 5 . 3 1}$ \\
Within subpopulations & & $0.047 \pm 0.026$ & $2237.79 \pm 36.69$ \\
\hline
\end{tabular}

Table 6. Trichechus manatus manatus. Sensitivity tests with varying mortality, carrying capacity ( $K_{i}$ no. of individuals), age at first offspring (FO), maximum reproductive age (MRA), and initial population size (IPS), including deterministic and stochastic mean annual rate of population change across the simulations (det-r and stoc-r $\pm \mathrm{SD}$ ), probability of quasi-extinction over $500 \mathrm{yr}(\mathrm{PE})$, and the mean final population size ( $\mathrm{N}$-final $\pm \mathrm{SD}$ ). The mean time to quasiextinction was $0 \mathrm{yr}$ in all cases except Mortality 3 (68.8 yr). Mortality 1 and 3 are half of and double the baseline parameters, respectively

\begin{tabular}{|lcccc|}
\hline Scenario & det-r & stoc-r & PE & N-final \\
\hline Mortality 1 & 0.308 & $0.063 \pm 0.02$ & 0 & $13600.1 \pm 31.39$ \\
Mortality 3 & 0.209 & $-0.034 \pm 0.028$ & 1 & 0 \\
$K=6700$ & 0.276 & $0.032 \pm 0.021$ & 0 & $6704.66 \pm 98.99$ \\
FO $=3$ yr & 0.305 & $0.055 \pm 0.024$ & 0 & $13590.05 \pm 41.56$ \\
FO = 6 yr & 0.284 & $0.038 \pm 0.022$ & 0 & $13541.93 \pm 93.16$ \\
MRA = 27 yr & 0.269 & $0.024 \pm 0.021$ & 0 & $12638.78 \pm 386.65$ \\
MRA = 39 yr & 0.276 & $0.032 \pm 0.021$ & 0 & $13420.99 \pm 170.79$ \\
IPS $=1675$ & 0.276 & $0.032 \pm 0.021$ & 0 & $13426.97 \pm 176.13$ \\
IPS $=3350$ & 0.276 & $0.032 \pm 0.021$ & 0 & $13420.27 \pm 167.59$ \\
IPS $=13400$ & 0.276 & $0.032 \pm 0.021$ & 0 & $13426.14 \pm 171.39$ \\
\hline
\end{tabular}



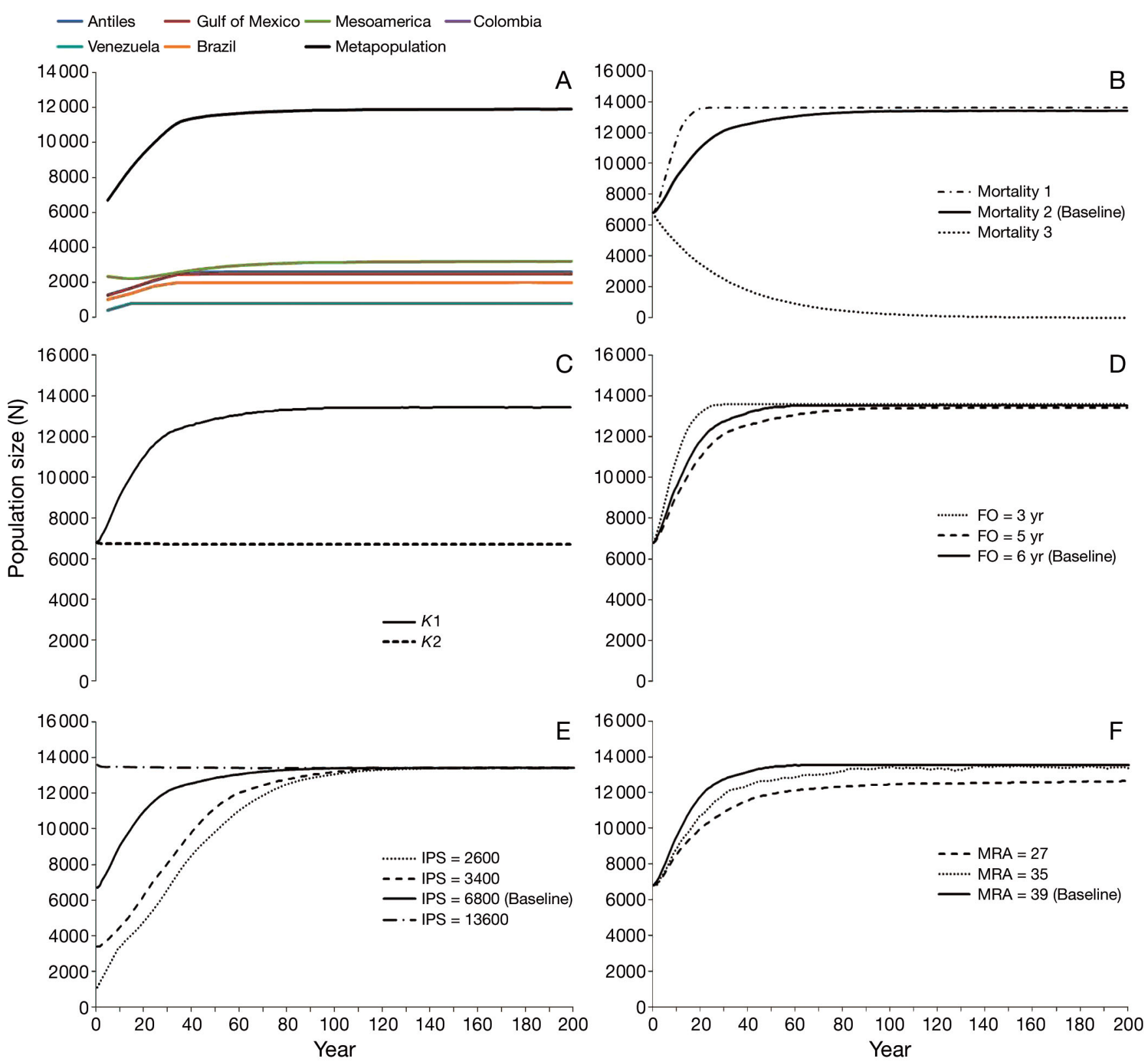

Fig. 2. Trichechus manatus manatus. Models showing the growth of Antillean manatee populations in number of individuals. (A) Model obtained for the 6 subpopulations and the metapopulation using baseline parameters. (B-F) Parameters of the baseline model varied during sensitivity testing for the metapopulation: (B) natural mortality, where Mortality 1 and 3 are half of and double the baseline parameters, respectively; $(C)$ carrying capacity $\left(K_{i} K 1: 13400 ; K 2: 6700 \text { individuals }\right)_{i}(\mathrm{D})$ age at first reproduction (FO); (E) initial metapopulation size (IPS); and (F) maximum reproductive age (MRA). Simulation tests were repeated 500 times and performed for $200 \mathrm{yr}$

estimated at 229.3 and $104 \mathrm{yr}$, respectively. With regard to natural catastrophes, variation in the intensity and frequency of hurricanes did not lead to any important change in the population growth curves (data not shown). Human impact and habitat fragmentation were the main factors that drastically caused changes in the simulated extinction process of the population (Table 7 ).
We varied 3 levels of both factors (human-related mortality and habitat fragmentation) in combined models (Fig. 5). The optimistic baseline scenario (Model 1) showed a positive growth of the population and an extinction time equal to 0 . Increasing humanrelated mortality led to extinction in all cases (Models $2,3,5,6,8$, and 9), but time to extinction was variable. A reduction in the survival probability of tran- 


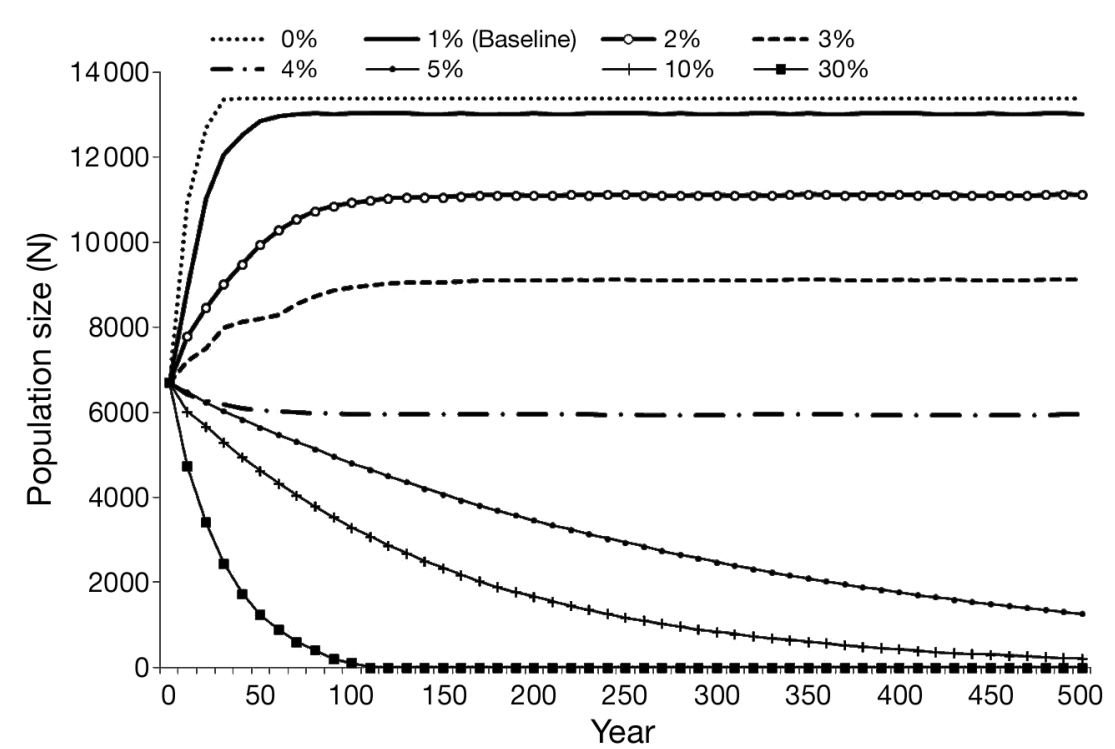

Fig. 3. Trichechus manatus manatus. Effect of several levels (\%) of humanrelated mortality on the Antillean manatee metapopulation over the next $500 \mathrm{yr}_{i} 1 \%$ is the assumed level for the baseline model calculated extinction time of only $41.5 \mathrm{yr}$.

\section{DISCUSSION}

In the case of the manatee, a PVA can be powerful for several reasons. First, the possibility of extinction highlights the necessity for adaptive management plans or the monitoring of current plans. Second, the PVA involves reviewing published and unpublished information. This process is helpful to identify gaps in the biology and conservation knowledge that need to be filled. Lastly, the PVA can lead us to detect particular cases or demographic processes that require urgent attention, e.g. countries where manatee populations are decreasing or their status is unknown (Table 1).

There are also some caveats for the use of this model. Its main weakness is the lack of certainty about the demographic characteristics, primarily regarding the estimated size of the population. The most robust data have been obtained in the Caribbean region, where habitat characteristics make it sients could be tolerable, if the human-related mortality is kept below 1\% (Model 4). However, a small increase in this rate $(5 \%)$ produced extinction of the population in $208.9 \mathrm{yr}$ (Model 5). The worst-case scenario occurred when $30 \%$ of the population was extracted every year, and just $30 \%$ of the transients between subpopulations survived (Model 9), with a

Table 7. Trichechus manatus manatus. Predictions for Antillean manatees, with varying human-related mortality (\% of deaths per year due to human causes) and habitat fragmentation (\% survival of transients; see Fig. 4). The results include deterministic and stochastic mean annual rates of population change across the simulations (det-r and stoc-r \pm SD), probability of quasiextinction over $500 \mathrm{yr}(\mathrm{PE})$, mean final population size (N extant $\pm \mathrm{SD}$ ), and the mean time (yr) to quasi-extinction (mean TE).

Predictions of Levels 3 and 4 of human-related mortality are not shown. Values of the baseline model are in bold

\begin{tabular}{|c|c|c|c|c|c|c|c|}
\hline $\begin{array}{l}\text { Combined } \\
\text { model }\end{array}$ & $\begin{array}{c}\text { Human-related } \\
\text { mortality }(\%)\end{array}$ & $\begin{array}{c}\text { Survival of } \\
\text { transients }(\%)\end{array}$ & det-r & stoc-r & $\mathrm{PE}$ & $\mathrm{N}$ extant & Mean TE \\
\hline \multirow{3}{*}{1 (baseline) } & Level $0(0)$ & Level 1 (95) & 0.28 & $0.04 \pm 0.02$ & 0.00 & $13349.40 \pm 77.98$ & 0.00 \\
\hline & Level 1 (1) & Level 1 (95) & 0.28 & $0.04 \pm 0.02$ & 0.00 & $13573.00 \pm 0.00$ & 0.00 \\
\hline & Level 2 (2) & Level 1 (95) & 0.28 & $0.04 \pm 0.02$ & 0.00 & $13348.80 \pm 84.38$ & 0.00 \\
\hline \multirow[t]{2}{*}{2} & Level 5 (5) & Level 1 (95) & 0.24 & $0.001 \pm 0.02$ & 1.00 & $199.47 \pm 21.30$ & $>500$ \\
\hline & Level 6 (10) & Level 1 (95) & 0.24 & $-0.01 \pm 0.03$ & 1.00 & $931.50 \pm 229.81$ & 307.00 \\
\hline \multirow[t]{2}{*}{3} & Level 7 (30) & Level 1 (95) & 0.24 & $-0.01 \pm 0.03$ & 0.99 & $732.67 \pm 16.50$ & 283.00 \\
\hline & Level 1 (1) & Level 2 (70) & 0.26 & $0.02 \pm 0.02$ & 0.00 & $11127.81 \pm 308.00$ & 0.00 \\
\hline 4 & Level 1 (1) & Level 3 (50) & 0.28 & $0.00 \pm 0.02$ & 0.00 & $7098.74 \pm 926.35$ & 0.00 \\
\hline 5 & Level 5 (5) & Level 3 (50) & 0.26 & $-0.01 \pm 0.02$ & 1.00 & 0.00 & 208.90 \\
\hline 6 & Level 7 (30) & Level 3 (50) & 0.24 & $-0.04 \pm 0.05$ & 1.00 & 0.00 & 55.80 \\
\hline \multirow[t]{2}{*}{7} & Level 1 (1) & Level 4 (30) & 0.28 & $-0.01 \pm 0.02$ & 1.00 & 0.00 & 229.30 \\
\hline & Level 1 (1) & Level 4 (30) & 0.28 & $-0.01 \pm 0.02$ & 1.00 & 0.00 & 226.00 \\
\hline 8 & Level 5 (5) & Level 4 (30) & 0.26 & $-0.02 \pm 0.03$ & 1.00 & 0.00 & 97.90 \\
\hline \multirow[t]{2}{*}{9} & Level 7 (30) & Level 4 (30) & 0.24 & $-0.06 \pm 0.05$ & 1.00 & 0.00 & 41.50 \\
\hline & Level 1 (1) & Level 5 (10) & 0.28 & $-0.02 \pm 0.02$ & 1.00 & 0.00 & 104.00 \\
\hline
\end{tabular}




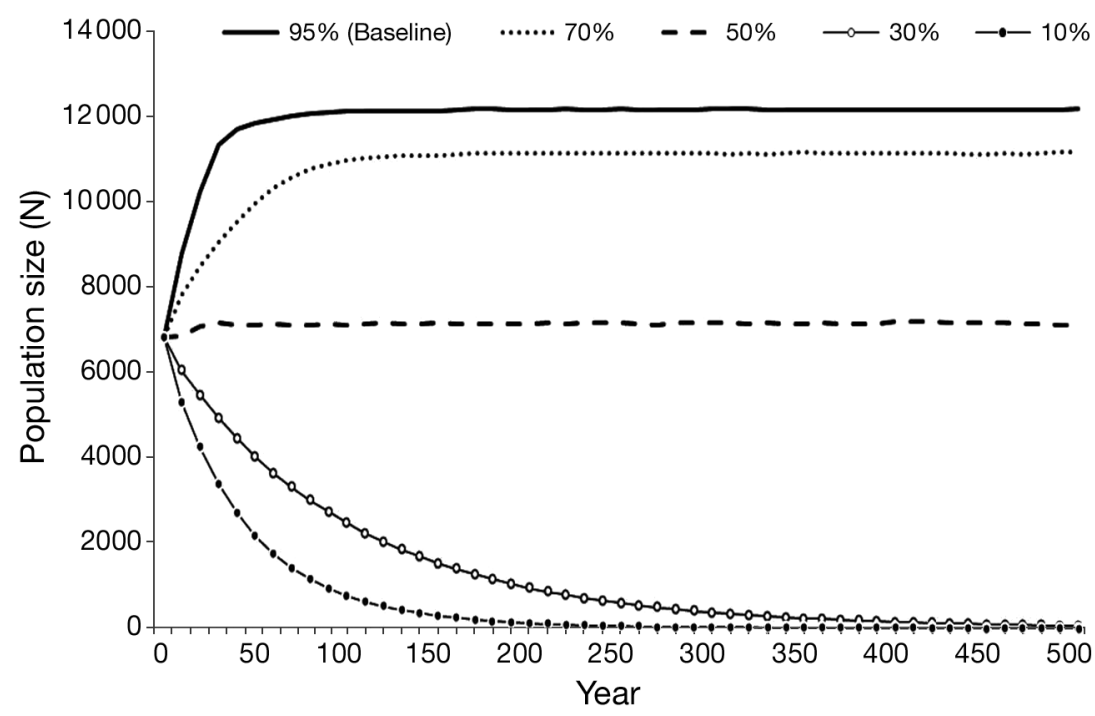

Fig. 4. Trichechus manatus manatus. Effect of several habitat fragmentation levels (\% survival of transients moving between subpopulations) on the Antillean manatee metapopulation over the next $500 \mathrm{yr}$; $95 \%$ survival is the assumed level for the baseline model possible to detect and count manatees using aerial surveys. Aerial surveys are useful to determine minimum population size, but they are probably not sufficient to asses a population size. Also, almost one half of the Trichechus manatus manatus population inhabits lagoons, streams, and floodplains. In this type of habitat, it is very difficult to detect manatees from the air, due to the low water transparency, dense vegetation, and access constraints. For those cases, it is important to develop new economic, practical, and suitable alternatives in order to estimate the manatee population size.

Our model did not take into account the trends of local populations (increase, decrease, stable, or unknown), because no quantitative data are avail-

\section{Human-related mortality (proportion of the population extracted per year)}

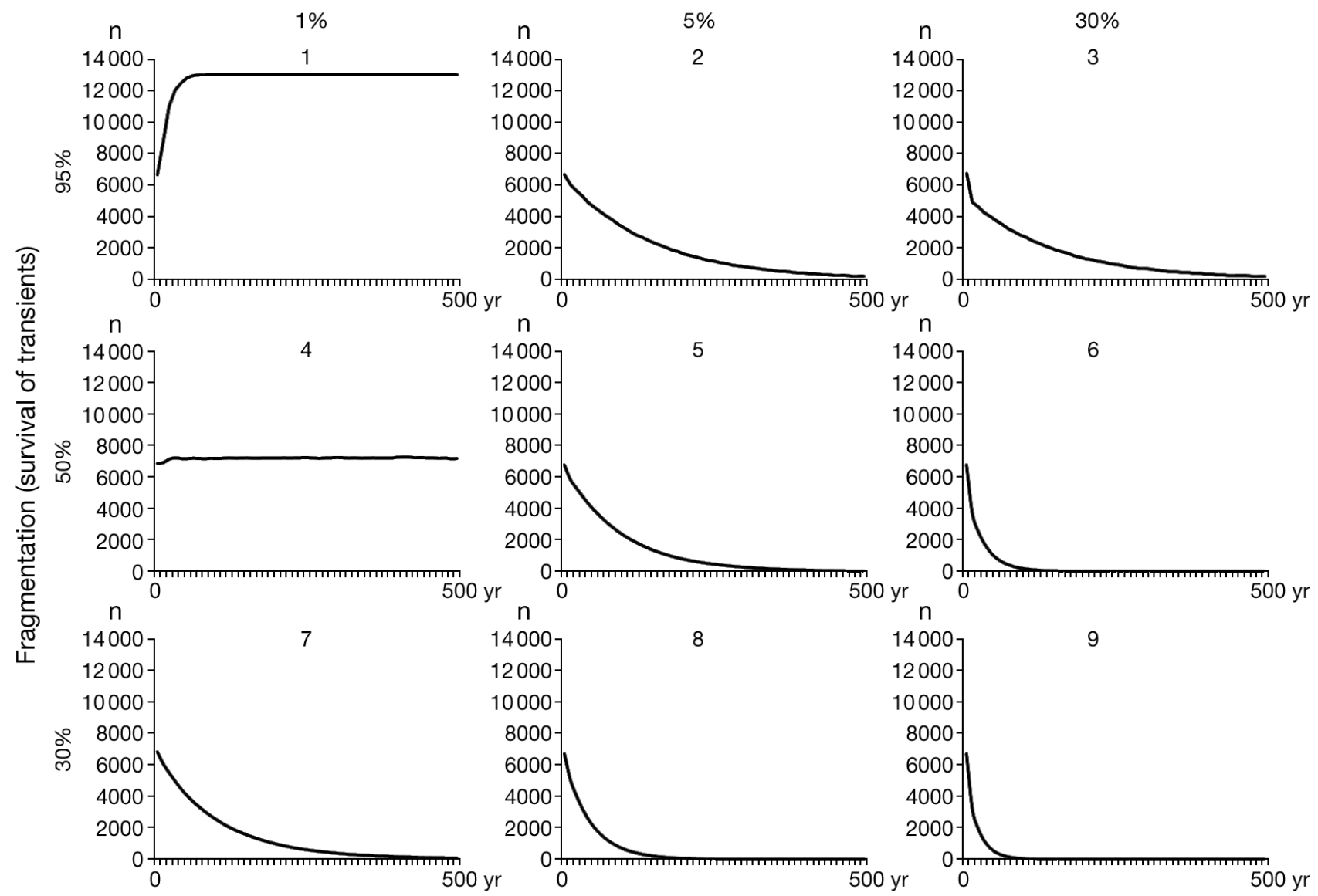

Fig. 5. Trichechus manatus manatus. Models 1 to 9, showing the combined effects of 3 levels of human-related mortality and 3 levels of fragmentation on Antillean manatee population dynamics. $y$-axes show the population size (number of individuals, $\mathrm{n}) ; \mathrm{x}$-axes show the simulation time (yr) 
able. However, it is important to emphasize that experts and local people throughout the region agree that the number of manatees sighted per year has decreased over time (information obtained by D. N. Castelblanco-Martínez in structured and semistructured interviews). The present model also assumes that all threats that affect Antillean manatees are equal between subpopulations. Further information is needed to refine the intensity of human pressure at several scales. As more information can be included in the model, predictions can be improved and the uncertainty reduced.

Another important source of uncertainty could be the parameter values for the life history of the Antillean manatee that were extrapolated from data on the Florida manatee. Studies on captive Antillean manatees show that the reproductive information is similar for both subspecies (Marmontel et al. 1992), and thus we expect that some values used for the Antillean subspecies are similar to the well-studied Florida manatee. The sensitivity tests showed that any slight differences between the values of the 2 subspecies parameters would not drastically affect the results of the model.

Our baseline model describes a metapopulation with a positive growth. The population dynamics of sirenians are such that mortality must be low in order to maintain a maximum potential annual rate of increase on the order of $5 \%$ (Marsh et al. 1984). Therefore, the observed baseline model growth rate is reasonable. In Florida, a viability analysis using VORTEX revealed negative growth of the population for all possible scenarios tested (Marmontel et al. 1997). The difference between Florida and our study could be related to intrinsic variations between subspecies and also differences in the values used in the model parameters, such as population size and mortality rates. A major difference between the Florida and Antillean manatee models is the estimated population size, about 7 times smaller for Florida. The population size is a determining parameter of the population dynamic model. In a smaller population, the number of interacting stochastic processes can decrease population growth and stability (Lacy 2000a).

Another important difference between Florida and Antillean manatees is the massive mortality associated with cold fronts and red tide episodes, which has a strong impact on the population. Florida manatees can experience over 300 to 400 deaths a year, as a result of cold stress or red tide exposure (Walsh et al. 2007). This is not the case for Antillean manatees, which inhabit the warm waters of tropical
America. No red tides affecting this subspecies have been documented.

Boat collisions account for about $25 \%$ of manatee deaths annually in Florida (Aipanjiguly et al. 2003). Although it is known that Antillean manatees are also affected by boat collisions (Mignucci-Giannoni et al. 2000, Borges et al. 2007), boat densities in developing countries seem to be remarkably lower than in Florida, and the overlap of manatees and human activities areas is less frequent and less invasive. For instance, in Kings Bay, Florida, the mean number of boats per day in a manatee area was 32.7, ranging from 1 to 79 (Buckingham et al. 1999), while on the Orinoco River, the mean number was 4.28 boats per day, ranging from 0 to 32 (CastelblancoMartínez 2004). For Antillean manatees, resource availability appears to determine habitat use, more than the boat traffic variable itself (Jiménez-Pérez 2005, Hamilton 2009). Although human populations in countries where Antillean manatees live are increasing (Wittemyer et al. 2008), there are not many areas yet where an intensive overlapping between manatees and boats occurs, as happens in Florida. This can be due to a lower density of manatees and/ or a lower density of humans occupying the coasts, with a conversely lower level of boating activity.

Although variation in natural catastrophes did not affect population growth, climate change can still affect manatees through habitat fragmentation, loss of suitable feeding areas, and general landscape modifications. Global climate change will affect the physical, biological, and biogeochemical characteristics of the oceans and coasts, affecting manatees living in estuaries and coastal ecosystems (Würsig et al. 2002). Furthermore, an important part of the Antillean manatee population lives in freshwater river systems and streams. Because the flooding regime is strongly related to large-scale climatic phenomena, there might be a perilous connection between climate change and the future prospects for those freshwater subpopulations (Arraut et al. 2010). Effects on the aquatic environment are especially difficult to predict because of the complex interactions between aquatic systems and climate, and will vary greatly between areas. Therefore, predictions of the effects of climate changes on species and populations are speculative (Würsig et al. 2002) and deserve deeper analysis.

There are other important effects of climatic change that were not taken into account because of the lack of sufficient information about their effect throughout the region. Identification of food resources, temporal dietary patterns, and foraging 
locations is necessary to detect changes in the feeding ecology of the species due to global warming. Long-term studies of individually identifiable animals can be expensive and require a long-term commitment for funding (Quintana-Rizzo \& Reynolds 2010). Furthermore, marking and tracking methods are generally too expensive for developing countries, and low-cost and practical monitoring strategies need to be identified to address multiple research objectives simultaneously (Quintana-Rizzo \& Reynolds 2010).

Antillean manatees still die as a direct result of human-related factors in all subpopulations. It is difficult to estimate accurately the current level of such deaths, but it is important to ensure that it is maintained below $5 \%$ of the estimated population size annually. Also, it should be noted that the model did not include another source of extraction from the natural population, such as orphaned calves as a collateral consequence of boat collision, hunting, entanglement, or natural death of the mother. Manatees have a long period of maternal care, and the mother's death directly implies the death of the dependent calf, if artificial care is not provided. There are relatively few manatee rehabilitation centers throughout the distribution area, and an unknown number of orphan calves still die due to the lack of appropriate detection, recovery, and subsequent care. Furthermore, most of the rehabilitated manatees remain in captivity, and in the majority of the cases there are no formal projects to reintroduce them back to the wild, as has been successfully done in Brazil (Lima et al. 2005,2007 ) and Belize (N. Auil pers. comm.). Improving and/or creating rehabilitation facilities to attend to emergencies is recommended (Quintana-Rizzo \& Reynolds 2010). Also, it is important to strengthen plans and actions to rehabilitate and release rescued manatees when their condition is appropriate for those actions.

In the majority of countries in which Antillean manatees occur, motorized boat traffic is currently relatively low (e.g. Castelblanco-Martínez 2004, Hamilton 2009), and except for Puerto Rico and Belize, collisions with boats do not represent the main threat to the subspecies. However, boat traffic is expected to increase in the future as local users increasingly abandon traditional dugout dories in favor of motor boats (Hamilton 2009). Recreational areas, often placed in shallow waters, should be carefully planned to avoid lethal encounters between manatees and boaters.

The survival of individuals moving between subpopulations is a success indicator of biological corri- dors, and therefore of habitat fragmentation levels. This model shows that not only the protection of areas intensively used by manatees, but also the maintenance of connectivity among subpopulations is necessary. The survival probability of transients can be increased by promoting and conserving natural corridors, thereby guaranteeing long-distance movements of some individuals each year. In this regard, some critical areas, including Panama and the Holbox region in Mexico, deserve particular attention. Panama represents the bridge between South America and Mesoamerica, and its preservation could be relevant to facilitate genetic exchange. The Holbox region (northeastern Yucatan Peninsula, Mexico) is very interesting in terms of genetic dispersion between the Gulf of Mexico and Caribbean region. Manatees have been reported in both Panama (Schad et al. 1981, Mou-Sue et al. 1990, Viquez 1993) and the Holbox areas (B. Morales-Vela pers. comm.), but there is no available information on their current conservation status or population size. Habitat fragmentation does not only impact the survival of manatees per se, but also has collateral effects. For example, fragmentation of rivers by dams might affect plant dispersal along river corridors (Jansson et al. 2000), and it could have an impact on the manatees' food resources. Additionally, pollution, environmental noise, boat traffic, and other factors are also important indirect collateral effects of fragmentation that can affect the viability of manatees. This aspect should be taken into account during the planning of ports, dams, bridges, channels, and any other alterations of the coastal shoreline and flow of rivers. Also, it is important to avoid fragmentation within subpopulations.

The review of published and unpublished literature about Antillean manatees raised an important issue: studies of the subspecies have been mostly addressed on a country-by-country basis. This is due to the fact that some countries have more governmental support for research and biological conservation than others. Countries such as Mexico, Belize, and Brazil have developed important long-term research projects on manatees, including genetics, radio tracking, and ecology. Those experiences should be communicated, and if possible, replicated in other countries with similar conditions. Antillean manatees can use extended areas and perform transboundary displacements (Morales-Vela \& PadillaSaldívar 2009). This wide use of habitat implies the need for international collaboration and must receive attention by scientists, governments, and managers of natural protected areas, in order to design conser- 
vation strategies not limited by national borders. We recommend establishing a multinational committee for regional Antillean manatee population monitoring, including conducting demographic censuses, establishing stranding networks, and providing environmental education.

Management decisions are based not only on whether the proposed strategy is sufficient to achieve recovery, but also on whether the likely benefit will justify the expenditure (Brook et al. 2000). Decisions by managers should take into account other factors that this study did not address, such as the economic and social costs of protecting Antillean manatees. However, this work provides information on critical points that will have to be further investigated in order to protect this endangered subspecies.

Acknowledgements. We thank T. Gerrodette, C. Beck, and R. K. Bonde for making helpful suggestions on the manuscript. B. Godley, R. Currey, and 2 anonymous referees provided helpful comments to improve this article.

\section{LITERATURE CITED}

Ackerman BB, Wright SD, Bonde R, Odell DK, Banowetz DJ (1995) Trends and patterns in mortality of manatees in Florida, 1974-1992. In: O'Shea TJ, Ackerman BB, Percival HF (eds) Population biology of the Florida manatee. Inform Tech Rep 1. US Department of the Interior, National Biological Service, Washington, DC, p 223-258

> Aipanjiguly S, Jacobson SK, Flamm R (2003) Conserving manatees: knowledge, attitudes, and intentions of boaters in Tampa Bay, Florida. Conserv Biol 17: 1098-1105

Akçakaya HR, Mills G, Doncaster CP (2007) The role of metapopulations in conservation. In: Macdonald DW, Service K (eds) Key topics in conservation biology. Blackwell Publishing, Oxford, p 64-84

- Anderson PK (2002) Habitat, niche, and evolution of sirenian mating systems. J Mamm Evol 9:55-98

> Arraut EM, Marmontel M, Mantovani JE, Novo EMLM, Macdonald DW, Kenward RE (2010) The lesser of two evils: seasonal migrations of Amazonian manatees in the Western Amazon. J Zool (Lond) 280:247-256

Borges JCG, Vergara-Parente JE, Alvite CMC, Marcondes MCC, Lima RP (2007) Embarcações motorizadas: uma ameaça aos peixes-bois marinhos (Trichechus manatus) no Brasil. Biota Neotrop 7:1-6

> Bossart GD, Meisner RA, Rommel SA, Ghim SJ, Jenson AB (2003) Pathological features of the Florida manatee cold stress syndrome. Aquat Mamm 29:9-17

Brook BW, O'Grady JJ, Chapman AP, Burgman MA, Akçakaya HR, Frankham R (2000) Predictive accuracy of population viability analysis in conservation biology. Nature 404:385-387

Buckingham CA, Lefebvre LW, Schaefer JM, Kochman HI (1999) Manatee response to boating activity in a thermal refuge. Wildl Soc Bull 27:514-522
Buergelt C, Bonde R, Beck C, O'Shea T (1984) Pathologic findings in manatees in Florida. J Am Vet Med Assoc 185:1331-1334

Caicedo-Herrera D, Trujillo F, Rodríguez CL, Rivera M (eds) (2005) Programa nacional de manejo y conservación de manatíes en Colombia. Ministerio del Medio Ambiente, Vivienda y Desarrollo Territorial. Fundación Omacha, Bogotá

Castelblanco-Martínez DN (2004) Peixe boi Trichechus manatus manatus na Orinoquia Colombiana: status de conservação e uso de habitat na época seca. MSc thesis, Instituto Nacional de Pesquisas da Amazônia/INPA, Manaus

Castelblanco-Martínez DN, Rosas FCW, Bermudez A, Trujillo-González T (2003) Conservation status of the West Indian manatee, Trichechus manatus manatus in the Middle Orinoco (Vichada, Colombia). 15th Biennial Conf Biol Mar Mamm, Greensboro, NC, p 30

Castelblanco-Martínez DN, Bermúdez-Romero AL, GómezCamelo I, Rosas FCW, Trujillo F, Zerda-Ordóñez E (2009) Seasonality of habitat use, mortality and reproduction of the vulnerable Antillean manatee Trichechus manatus manatus in the Orinoco River, Colombia: implications for conservation. Oryx 43:235-242

Courchamp F, Clutton-Brock T, Grenfell B (1999) Inverse density dependence and the Allee effect. Trends Ecol Evol 14:405-410

Deutsch CJ, Reid JP, Bonde RK, Easton DE, Kochman HI, O'Shea TJ (2003) Seasonal movements, migratory behavior and site fidelity of West Indian manatees along the Atlantic Coast of the United States. Wildl Monogr 151:1-77

Deutsch CJ, Self-Sullivan C, Mignucci-Giannoni A (2008) Triechus manatus. IUCN (2011) IUCN Red List of Threatened Species, Version 2011.2. www.iucnredlist.org. Accessed 22 May 2012

> Domning DP, Hayek LAC (1986) Interspecific and intraspecific morphological variation in manatees (Sirenia, Trichechus). Mar Mamm Sci 2:87-144

Falcon-Matos L, Mignucci-Giannoni AA, Toyos-González GM, Bossart GD, Meisner RA, Varela RA (2003) Evidence of a shark attack on a West Indian manatee (Trichechus manatus) in Puerto Rico. J Neotrop Mamm 10:6-11

Garcia-Rodriguez AI, Bowen BW, Domning D, MignucciGiannoni AA and others (1998) Phylogeography of the West Indian manatee (Trichechus manatus): How many populations and how many taxa? Mol Ecol 7:1137-1149

Giri C, Ochieng E, Tieszen LL, Zhu Z and others (2011) Status and distribution of mangrove forests of the world using earth observation satellite data. Glob Ecol Biogeogr 20:154-159

Guichard C, Ellis S, Matamoros Y, Seal U (eds) (2001) Análisis de la viabilidad poblacional y del hábitat del manatí en México. Conservation Breeding Specialist Group (SSC/IUCN), Apple Valley, MN

Hamilton ESS (2009) Effects of boat disturbance on Antillean manatee space use and foraging habitat. MSc thesis, Simon Fraser University, Burnaby

Hanski I, Gilpin M (1991) Metapopulation dynamics: brief history and conceptual domain. Biol J Linn Soc 42:3-16

Hartman DS (1979) Ecology and behavior of the manatee (Trichechus manatus) in Florida. Spec Publ 5. American Soviety of Mammalogists, Lawrence, KS

Hassell MP (1975) Density-dependence in single-species populations. J Anim Ecol 44:283-295 
Haubold EM, Deutsch C, Fonnesbeck C (2006) Final biological status review of the Florida manatee (Trichechus manatus latirostris). Florida Fish and Wildlife Conservation Commission St. Petersburg, FL

$>$ Heinsohn GE, Spain AV (1974) Effects of a tropical cyclone on littoral and sub-littoral biotic communities and on a population of dugongs (Dugong dugon, Muller). Biol Conserv 6:143-152

Heinsohn R, Lacy RC, Lindenmayer DB, Marsh H, Kwan D, Lawler IR (2004) Unsustainable harvest of dugongs in Torres Strait and Cape York (Australia) waters: two case studies using population viability analysis. Anim Conserv 7:417-425

Hernández P, Reynolds JE III, Marsh H, Marmontel M (1995) Age and seasonality in spermatogenesis of Florida manatees. In: O'Shea TJ, Ackerman BB, Percival HF (eds) Population biology of the Florida manatee. Inform Tech Rep 1. US Department of the Interior, National Biological Service, Washington, DC, p 84-97

> Hunter ME, Auil-Gomez NE, Tucker KP, Bonde RK, Powell J, McGuire PM (2010) Low genetic variation and evidence of limited dispersal in the regionally important Belize manatee. Anim Conserv 13:592-602

Irvine AB (1983) Manatee metabolism and its influence on distribution in Florida. Biol Conserv 25:315-334

Jansson R, Nilsson C, Dynesius M, Andersson E (2000) Effects of river regulation on river-margin vegetation: a comparison of eight boreal rivers. Ecol Appl 10:203-224

Jiménez-Pérez I (2005) Development of predictive models to explain the distribution of the West Indian manatee Trichechus manatus in tropical watercourses. Biol Conserv 125:491-503

Jiménez-Pérez I (1998) Ecología y conservación del manatí (Trichechus manatus L.) en el noreste de Costa Rica. Base de datos de los humedales del noreste de Costa Rica asociada a un sistema de información geográfica. MS thesis, Universidad Nacional, Heredia

Lacy RC (2000a) Considering threats to the viability of small populations. Ecol Bull 48:39-51

Lacy RC (2000b) Structure of the VORTEX simulation model for population viability analysis. Ecol Bull 48:191-203

Langtimm CA, Beck CA (2003) Lower survival probabilities for adult Florida manatees in years with intense coastal storms. Ecol Appl 13:257-268

Langtimm CA, O'Shea TJ, Pradel R, Beck CA (1998) Estimates of annual survival probabilities for adult Florida manatees (Trichechus manatus latirostris). Ecology 79: 981-997

Langtimm CA, Beck CA, Edwards HH, Fick-Child KJ, Ackerman BB, Barton SL, Hartley WC (2004) Survival estimates for Florida manatees from the photo-identification of individuals. Mar Mamm Sci 20:438-463

Langtimm CA, Krohn MD, Reid JP, Stith BM, Beck CA (2006) Possible effects of the 2004 and 2005 hurricanes on manatee survival rates and movement. Estuaries Coasts 29:1026-1032

Lefebvre LW, Marmontel M, Reid JP, Rathbun GB, Domning DP (2001) Distribution, status, and biogeography of the West Indian manatee. In: Woods CA, Sergile FE (eds) Biogeography of the West Indies: patterns and perspectives. CRC Press, Boca Raton, FL, p 425-474

Lima RP, Alvite CMC, Vergara-Parente JE, Castro DF, Paszkiewicz E, Gonzalez M (2005) Reproductive behavior in a captive-released manatee (Trichechus manatus manatus) along the northeastern coast of Brazil and the life history of her first calf born in the wild. Aquat Mamm 31:420-426

Lima RP, Alvite CM, Vergara-Parente JE (2007) Protocolo de reintrodução de peixes-bois-marinhos no Brasil. IbamaMA, Instituto Chico Mendes, São Luis

Lindenmayer D, Clark T, Lacy R, Thomas V (1993) Population viability analysis as a tool in wildlife conservation policy: with reference to Australia. Environ Manag 17: 745-758

Lindenmayer DB, Burgman MA, Akçakaya HR, Lacy RC, Possingham HP (1995) A review of the generic computer programs ALEX, RAMAS/space and VORTEX for modelling the viability of wildlife populations. Ecol Model 82: 161-174

Ludwig D (1996) Uncertainty and the assessment of extinction probabilities. Ecol Appl 6:1067-1076

Marmontel M (1995) Age and reproduction in female Florida manatees. In: O'Shea TJ, Ackerman BB, Percival F (eds) Population biology of the Florida manatee. Inform Tech Rep 1. US Department of the Interior, National Biological Service, Washington, DC, p 98-119

Marmontel M, Odell DK, Reynolds JE (1992) Reproductive biology of South American manatees. In: Hemlett WC (ed) Reproductive biology of South American vertebrates. Springer-Verlag, New York, NY, p 295-312

Marmontel M, O'Shea TJ, Kochman HI, Humphrey SR (1996) Age determination in manatees using growthlayer-group counts in bone. Mar Mamm Sci 12:54-88

Marmontel M, Humphrey SR, O'Shea TJ (1997) Population viability analysis of the Florida manatee (Trichechus manatus latirostris), 1976-1991. Conserv Biol 11: $467-481$

> Marsh H, Heinsohn GE, Marsh LM (1984) Breeding cycle, life history and population dynamics of the dugong, Dugong dugon (Sirenia: Dugongidae). Aust J Zool 32: $767-788$

> McKillop HI (1985) Prehistoric exploitation of the manatee in the Maya and Circum-Caribbean Areas. World Archaeol 16:337-353

Michener WK, Blood ER, Bildstein KL, Brinson MM, Gardner LR (1997) Climate change, hurricanes and tropical storms, and rising sea level in coastal wetlands. Ecol Appl 7:770-801

Mignucci-Giannoni AA, Montoya-Ospina RA, JimenezMarrero NM, Rodriguez-Lopez MA, Williams EH, Bonde RK (2000) Manatee mortality in Puerto Rico. Environ Manag 25:189-198

Miller PS, Lacy RC (2005) VORTEX: a stochastic simulation of the extinction process. Version 9.50. Chicago Zoological Society, Brookfield, IL

Morales-Vela B, Padilla-Saldívar J (2009) Demografía, ecología y salud de la población de manatíes (Trichechus manatus manatus) en Quintana Roo, y su variación y representación genética en México. Informe Técnico Final. El Colegio de la Frontera Sur, Proyecto SEMARNAT/ CONACYT 2002-C01-1128. Chetumal, Quintana Roo

Morales-Vela B, Padilla-Saldivar JA, Sanvicente-López M (2002) Mortandad de manatíes en la Bahía de Chetumal y riesgos actuales. In: Rosado-May FJ, Romero-Mayo R, De Jesus-Navarrete A (eds) Contribuciones de la ciencia al manejo costero integrado de la Bahia de Chetumal y su área de influencia. Universidad de Quintana Roo, Chetumal, p 67-72

Morris WF, Bloch PL, Hudgens BR, Moyle LC, Stinchcombe JR (2002) Population viability analysis in endangered 
species recovery plans: past use and future improvements. Ecol Appl 12:708-712

Mou-Sue L, Chen DH, Bonde R, O'Shea T (1990) Distribution and status of manatees (Trichechus manatus) in Panamá. Mar Mamm Sci 6:234-241

Nourisson C, Morales-Vela B, Padilla-Saldívar J, Tucker K and others (2011) Evidence of two genetic clusters of manatees with low genetic diversity in Mexico and implications for their conservation. Genetica 139:833-842

O'Shea TJ, Hartley WC (1995) Reproduction and early-age survival of manatees at Blue Spring, Upper St. Johns River, Florida. In: O'Shea TJ, Ackerman BB, Percival HF (eds) Population biology of the Florida manatee. Inform Tech Rep 1. US Department of the Interior, National Biological Service, Washington, DC, p 157-176

Odell DK, Bossart GD, Lowe MT, Hopkins TD (1995) Reproduction of the West Indian manatee in captivity. In: O'Shea TJ, Ackerman BB, Percival HF (eds) Population biology of the Florida manatee. Inform Tech Rep 1. US Department of the Interior, National Biological Service, Washington, DC, p 192-193

Ortiz-Royero JC (2007) Huracanes y tormentas tropicales en el Mar Caribe colombiano desde 1900. Bol Cient Cent Invest Oceanogr Hidrogr Cartagena 25:54-60

Pomeroy P (2011) Reproductive cycles of marine mammals. Anim Reprod Sci 124:184-193

Preen AR, Marsh H (1995) Response of dugongs to largescale loss of seagrass from Hervey Bay, Queensland. Aust Wildl Res 22:507-519

Quintana-Rizzo E, Reynolds JEI (2010) Regional management plan for the West Indian manatee (Trichechus manatus). CEP Tech Rep. United Nations Environment Programme, Kingston

Rathbun GB, Reid JP, Bonde R, Powel JA (1995) Reproduction in free-ranging Florida manatees. In: O'Shea TJ, Ackerman BB, Percival HF (eds) Population biology of the Florida manatee. Inform Tech Rep 1. US Department of the Interior, National Biological Service, Washington, DC, p 135-156

Reid JP, Bonde RK, O'Shea TJ (1995) Reproduction and mortality of radio-tagged and recognizable manatees on the Atlantic Coast of Florida. In: O'Shea TJ, Ackerman BB, Percival HF (eds) Population biology of the Florida manatee. Inform Tech Rep 1. US Department of the Interior, National Biological Service, Washington, DC, p 171-191

Editorial responsibility: Brendan Godley, University of Exeter, Cornwall Campus, UK
Reynolds JE III (1979) The semisocial manatee. Nat Hist 88: 44-53

Reynolds JE III, Ferguson JC (1984) Implications of the presence of manatees (Trichechus manatus) near the Dry Tortugas Islands. Fla Sci 47:187-189

Saunders DA, Hobbs RJ, Margules CR (1991) Biological consequences of ecosystem fragmentation: a review. Conserv Biol 5:18-32

Schad RC, Montgomery GG, Chancellor D (1981) La distribución y frecuencia del manatí en el lago Gatun y en el Canal de Panamá. Conciencia 8:1-4

Self-Sullivan C, Mignucci-Giannoni A (2008) Trichechus manatus ssp. manatus. IUCN 2011. IUCN Red List of Threatened Species. Version 2011.2. www.iucnredlist. org (accessed on 22 May 2012)

Shaffer ML (1981) Minimum population sizes for species conservation. Bioscience 31:131-134

Shaffer ML (1990) Population viability analysis. Conserv Biol 4:39-40

Short F, Carruthers T, Dennison W, Waycott M (2007) Global seagrass distribution and diversity: a bioregional model. J Exp Mar Biol Ecol 350:3-20

> Uezu A, Metzger JP, Vielliard JME (2005) Effects of structural and functional connectivity and patch size on the abundance of seven Atlantic forest bird species. Biol Conserv 123:507-519

- Vianna JA, Bonde RK, Caballero S, Giraldo JP and others (2006) Phylogeography, phylogeny and hybridization in trichechid sirenians: implications for manatee conservation. Mol Ecol 15:433-447

Viquez D (1993) Situación del manatí (Trichechus manatus) en la República de Panamá. Ministerio de Planificación y Política Económica- Comisión Nacional del Medio Ambiente, Ciudad de Panamá

- Walsh CJ, Stuckey JE, Cox H, Smith B and others (2007) Production of nitric oxide by peripheral blood mononuclear cells from the Florida manatee, Trichechus manatus latirostris. Vet Immunol Immunopathol 118:199-209

Wittemyer G, Elsen P, Bean WT, Burton ACO, Brashares JS (2008) Accelerated human population growth at protected area edges. Science 321:123-126

Würsig B, Reeves RR, Ortega-Ortiz JG (2002) Global climate change and marine mammals. In: Evans PGH, Raga JA (eds) Marine mammals: biology and conservation. Kluwer Academic/Plenum Publishers, New York, NY, p 589-608

Submitted: November 7, 2011; Accepted: May 28, 2012

Proofs received from author(s): July 30, 2012 